\title{
Price Expectations and Purchase Decisions: Evidence from an Online Store Experiment
}

\author{
Sudipt Roy • Tat Chan • Amar Cheema
}

Published online: 18 March 2014

(C) Springer Science+Business Media New York 2014

\begin{abstract}
In this paper, we study the role of consumer price expectations in influencing consumer purchase decisions. Specifically, we examine the drivers of relative dominance of two price expectations - one formed prior to store visit (PRIOR) and the other about price in other stores (POST) formed after being exposed to focal store price. We collect the data from an online store shopping environment, allowing participants to make real purchase decisions. We have identified two distinct classes of shopping behaviors in our datainside-focused (IF) and outside-looking (OL). Purchase decisions of the former are mainly driven by PRIOR while that of the latter by POST. At constant cost, we show that a promotion scheme with deep discounts (e.g., $5 \%$ for 3 weeks or $15 \%$ price cut in the first week) boosts sales more than the one with shallow discount (e.g., $3 \%$ for 5 weeks). This increase comes mainly from the OL class, which is more sensitive to price changes. We further demonstrate how stores should manage consumer price expectations to maximize the sales lift during price promotions.
\end{abstract}

Keywords Price expectation $\cdot$ Reference price $\cdot$ Promotion

Electronic supplementary material The online version of this article (doi:10.1007/s40547-014-0010-3) contains supplementary material, which is available to authorized users.

\section{S. Roy}

Indian School of Business, Gachibowli, Hyderabad 500032, India e-mail: Sudipt_Roy@ISB.edu

\section{T. Chan $(\bowtie)$}

Olin Business School, Washington University in St. Louis, CB1133, One Brookings Drive, St. Louis, MO 63130, USA

e-mail: CHAN@wustl.edu

\section{A. Cheema}

McIntire School of Commerce, University of Virginia, Rouss \& Robertson Halls, 125 Ruppel Dr., Charlottesville, VA 22903, USA e-mail: cheema@virginia.edu

\section{Introduction}

Prior to a store visit, most consumers plan what products/ items to purchase [1] and form expectations about the prices they would pay for those items. Price expectations are used as reference points to help make final purchase decisions [2]. Assume that two consumers, A and B, plan to buy a particular brand of orange juice in the same store. Consumer A expects to pay $\$ 7$ and B $\$ 5$ for the product, but both find the store price to be $\$ 6$. It is reasonable to predict that $B$ is less likely to buy it than A. There are at least two behavioral explanations for this prediction. The first is that $\mathrm{B}$ compares her prior expectation and the actual price of the store. Her transaction utility (the psychological loss when compared to a reference price) [3] is negatively affected because the prior expectation is lower than the actual price. Another explanation is that $\mathrm{B}$ defers until next purchase occasion in a different store (or sometimes in the same store at a later week) because she expects to pay a lower price then.

Reference prices are invariably linked to consumers' price expectations. Consistent with the behavioral explanation given above, there can be at least two distinct price expectations that influence purchase decisions. On one hand, Thaler [3] treats the expectation of the store price as an internal reference point in the prospect theory framework [4]. Several empirical papers have tested the predictions of this theory by examining how consumers respond to psychological losses and gains [5]. On the other hand, in a rational utility maximizing framework, the consumer's price expectation is the expected cost of alternative purchase options, i.e., price at a different store or same store in a later week. Several marketing studies, using either the analytical [6] or the empirical approach [7], are based on this framework. As we will discuss later, the two frameworks need not be mutually exclusive of each other - depending on the amount of cognitive resources consumers are willing to 
invest during the shopping process, they may switch from using one type of expectation to another.

Experience with changing price levels inside stores has been traditionally identified as a primary information source for consumers to update internal reference points [8] or the expected cost of alternative purchasing options [9]. The "adaptive expectation" approach proposed in Nerlove [10] was one of the first to model how consumers update expectations. Consumers may follow different routes for updating expectations. As we shall explain later, fluctuations in prices may have different impacts on different consumers in updating their expectations; this is moderated by the amount of cognitive resources they invest during the shopping process.

We study the impact of price expectations on converting consumers' planned purchases into actual purchases in a store and investigate when and how the effect of one type of price expectation dominates the effect of another. This is the first marketing study to disentangle the two effects. The major reason for the absence of such studies is the identification problem. Since price expectations are unobservable and both explanations can lead to the same observable outcomes, as the above example has illustrated, secondary consumer data do not allow us to distinguish the impacts of the two expectations on purchases. To overcome this data problem, we designed a laboratory experiment where participants shop at an online store under a realistic environment, in which they make actual purchases by spending real money. This experiment enables us to collect detailed information. Specifically, participants first report what product items they plan to purchase and how much they expect to pay for those items in the store, before they are exposed to actual prices (we label this as PRIOR). After the shopping process, they report again how much they expect to pay for those planned purchase items if they were to buy them later (we label this as POST). By randomly assigning participating consumers into different manipulated pricing conditions, the online experiment allows us to study how price changes inside the store affect the updating process of consumer price expectations and as a result how they impact purchase decisions. Hence, this approach is superior to the method of intercepting consumers in real stores.

We develop an econometric model to jointly estimate price expectation formations as well as purchase decisions from data. We find that there exist two distinct classes of behaviors among our participants. For one class (about $30 \%$ of the total), the purchase decisions in our store are strongly affected by prices that consumers expect to pay in outside stores. Changes in current store prices significantly impact both of the price expectations - PRIOR and POST - for this class. We call this the "outside-looking" class as its purchase decisions are driven by the economic gain and loss compared with other stores. Purchase decisions of the dominant class (about $70 \%$ of the total), however, are primarily driven by the comparison of prior price expectations and actual prices of the store. Expectations from outside stores do not have much impact in the purchase decisions of this class. Both of the price expectations in this class are stable over time. We call this the "inside-focused" class. We confirm the existence of threshold below which any price reduction is not noticed by the shoppers and also find demographics, product preferences, and the price stimuli may move shoppers from one class to the other. For instance, participants are more likely to belong to the inside-focused class when prices decrease.

Contributions from this study are twofold. From the academic perspective, this paper is the first in the marketing literature to provide evidence that, under different market environments, consumers' purchase decisions are influenced by the two types of price expectations in different ways. We argue that our results are consistent with predictions from dual-process models of information processing. The results also help retailers to understand the impact of different pricing and promotion strategies and offer important managerial takeaways. We show that, at constant cost, a promotion scheme with deep discounts (e.g., $5 \%$ price cut over 3 weeks or $15 \%$ price cut in the first week) increases store sales more than several shallow discounts over a longer duration (e.g., $3 \%$ price cut over 5 weeks). We also show that the former promotion scheme will switch consumers to the insidefocused class, whose purchase decisions are influenced by the disconfirmation between store price and PRIOR. Further, we illustrate the importance of managing price expectations when running a price promotion. When consumers are informed of the promotion in advance (through say, feature advertisements), they will suitably downgrade their PRIOR; thus, store sales may increase less. By managing consumers' POST (through say, on-the-shelf displays) when they are inside the store, on the other hand, could help make the promotion much more effective.

The rest of the paper is organized as follows: in Section 2, we provide a theoretical foundation for our study and develop hypotheses. We discuss the online store shopping experiment and the collected data in Section 3. In Section 4, we provide a detailed description of our model and the estimation approach, and in Section 5, we present and discuss estimation results. We follow-up with the managerial implications in Section 6, and finally, Section 7 concludes this study and acknowledges some of its limitations.

\section{A Conceptual Framework for Price Expectations}

In this section, we apply dual-process models of information processing to develop hypotheses that address issues related to our research objective. We conceptualize that the heterogeneity in the primacy of either of the two price expectations in 
purchase decisions and updating processes for the expectations are driven by the different levels of effort that consumers invest in processing information. We also examine various factors that impact consumers' effort level.

\subsection{Dual-Process Models of Information Processing}

Theories in this domain predict when consumers choose between high or low resource-intensive processing strategies and how this choice may be influenced by individual and contextual differences. Cacioppo and Petty [11] suggest an Elaboration Likelihood Model (ELM) where individuals choose the effort level. Individuals usually tend to take a low-effort "peripheral route," but they will take a high-effort "central route" to process information when they have the motivation to do so. Similar models have been developed, among others, by Shiffrin and Schneider [12], Chaiken [13], and Sloman [14] (see [15] for a comprehensive review). Stanovich and West [16] label low and high resourceintensive cognitive processes as system 1 and system 2, respectively. In a review paper, Kahneman [17] explains that "the operations of system 1 are fast, automatic, effortless, associative, and often emotionally charged." Operations of system 2, on the other hand, are "slower, serial, effortful, and deliberately controlled."

In a direct application of ELM to the purchasing context, Inman et al. [18] have shown that consumers who process via the high-effort route react to price cuts on the basis of the magnitude of the savings. For consumers who process via a low-effort route, however, a promotional signal like a sale sign is enough to influence their purchase behavior. Consistent with the latter effect, Lynch and de Chernatony [19] suggest that emotional cues are more effective for consumers who do not carefully process information. It is important to note that a low-effort process does not imply poor purchasing decisions. As Kahneman [17] argues, system 1 can be "powerful and accurate" if skill has been acquired through prolonged practice. Because they already have the necessary skill, consumers do not need to invest high effort in processing information.

Applying the dual-process models to our online store context, we note that the internal reference price (PRIOR) refers to the price that participants expect to pay in the store prior to his/ her exposure to the actual price. This expectation may be formed based on past experiences. As we shall explain in the next section, the expected price of alternative purchasing options (POST) is collected after participants have finished shopping. While forming PRIORs and planning which products to purchase require effort, it is relatively automatic and effortless to recall PRIORs when participants are inside the store. Dual-process models suggest that the readily available PRIOR is used first to compare with current prices; hence, it will be a major determinant in consumer purchase decisions.
However, for POST to play an important role in purchase decisions, it requires more individual effort in information processing. This is because after observing store prices, participants have to reconsider the alternative options of buying in another store (or buying later in the same store) and compare with current prices to make purchase decisions. This allows people to decide whether to postpone the purchase and avoid potential regret at a later time. Therefore, only a stronger motivation (e.g., a higher expected benefit from the purchases) would cause participants put in the requisite effort in information processing. As a result, their price expectations are likely to be updated with observed store price changes and, once expectations are updated, they are also likely to reconsider their outside options by comparing the updated POSTs with store prices.

Participants who exert relatively lower effort in price information processing, relying on PRIOR in purchase decisions, are less likely to use current prices to update their POST as well as their price expectation for the next visit to our online store (i.e., PRIOR for the next trip). Hence, both of these expectations are more stable for low-effort purchases than for high-effort purchases, the latter being more likely to update and use POST in decision-making. Furthermore, since individuals making low-effort purchases are less likely to pay attention to current price changes, they may also be less price sensitive than individuals making high-effort purchases. Therefore, the difference in the effort level in information processing among individuals, via the dual-process models, can explain consumer heterogeneity in purchasing and updating behaviors.

While we cannot directly observe the effort level of consumers, dual-process models predict that the existence of lowand high-effort price information processing will lead to distinct types of purchasing behavior and expectations updating in our data. As a result, we propose and test the following hypotheses:

H1 Inside the store, there are two types of purchase decisions - the low-effort type is more influenced by PRIOR and less influenced by price changes inside the store, while the high-effort type is more influenced by POST and by price changes.

H2 Consumers making low-effort purchases are less likely to update their price expectations compared to those making high-effort purchases.

Based on past research [8], we further hypothesize that consumers have a zone of insensitivity. If the price stimuli compared with PRIOR and POST are not strong enough (i.e., within the zones of insensitivity), consumers may be less likely to change purchase decisions and update their price expectations by incorporating current prices. 


\subsection{Antecedents of Effort}

The source of motivation to exert effort could be situationspecific or individual-specific. In the shopping context, price changes within the store may alter consumers' perception for the need of a high-effort mode of information processing. Observing a price decrease may have generated a large enough psychological gain for the consumers in the first stage so that they do not need to process further information. However, an unexpected price increase may induce consumers' need for considering outside options, hence creating a motivation for information processing.

Furthermore, consumers may invest a lower effort in processing price information when they are planning to buy their favorite brands because they are more knowledgeable about the price. However, they may also have a high motivation for effort since a higher product preference implies a higher expected gain for the invested effort. Finally, some consumers may have a tendency for higher involvement than others. For example, frequent shoppers may be skilled in making purchase decisions and hence are more likely to use low effort that is fast and effortless [17]. It could also be driven by demographic factors. Low-income households with limited budget for shopping may have a higher motivation to compare prices carefully with outside stores. Therefore, we propose and test the following hypothesis:

H3 Consumers will switch between high-effort and loweffort purchase decisions depending on situationspecific factors such as price stimuli inside the store and brands planned to purchase. Individual-specific factors such as prior shopping experience and household income will also affect the type of purchase decision.

\section{The Online Store Experiment}

We designed an online grocery store to study household shopping behavior for a period of 5 weeks between September 11 and October 13, 2006. The shopping environment was as close as possible to any functioning store, and all price change conditions were controlled within the range of outside store price changes. In our online store, shoppers made actual purchases by spending real money. We collected detailed information about the participants' plans for purchases, price expectations, and purchase behaviors.

\subsection{Experiment Setup}

Participants were screened to select only those who were primary shoppers for their family and made at least one shopping trip every 2 weeks. Fifty-nine adults $(95 \%$ of them were women) were invited to participate in this study. Table 1 lists demographic characteristics for the participants.

The online store was situated in an experimental laboratory in a university. Each participant was provided with a dedicated computer terminal to shop during the visit to the store. The store stocked 89 stock keeping units (SKUs) in nine product categories (see Web Appendix 1), which remained unchanged throughout the experiment. These categories and SKUs were picked based on screening responses, being commonly purchased items. Detailed pricing data from a local grocery chain, both for online and offline stores, was collected for several months preceding the study. We used these data to calculate the average price and price changes for each of the SKUs.

Each participant was given a budget of $\$ 15$ per visit. She could spend any amount (including none at all) within that budget, and actual delivery of purchased groceries was managed through a local grocery chain that provided this service for a fee. ${ }^{1}$ Any unspent amount from the budget was refunded to the participant as cash. Hence, during shopping, our participants faced a choice between buying from the store or taking the cash and spending on any outside stores. On an average, in each weekly visit, a participant spent $\$ 12.27$ (minimum $\$ 0$ and maximum $\$ 15$ ) every week and bought 5.58 (minimum 0 and maximum 11) unique SKUs.

\subsection{Data Collection}

In the first visit, we collected the participants' brand preference and demographics. In each of the four subsequent visits, the participants had to sequentially complete a pre-purchase questionnaire, shop online, and then complete a post-purchase questionnaire. The first questionnaire collected information about the participants' purchase plan, the price they expected to pay in the store (PRIOR) for each of the SKUs that they planned to buy, and their confidence in the reported expectation. ${ }^{2}$ After the shopping process was over, the second questionnaire asked participants the price they expected to pay for the next shopping occasion (i.e., POST) for each of the SKUs that they intended to buy or actually bought in the current trip and their confidence in the reported expectation. Since our store had limited product offerings, our participants also visited other stores on a regular basis during the experiment period. We find in the data a low association between the POST of an item in a week and its corresponding PRIOR in

\footnotetext{
${ }^{1}$ To control the substantial delivery cost, a coin was tossed at the end of each interaction cycle to find out whether the participant gets her groceries or \$15 in cash. Of the 290 participant-weeks, 143 resulted in home deliveries.

${ }^{2}$ We only asked participants to report PRIORs for those SKUs they planned to purchase for two reasons: first, it would be too time consuming if participants had to report PRIORs for all 89 SKUs every week. Second and more important, it is not realistic that participants would be able to form price expectations for all SKUs including those they had never intended to purchase.
} 
Table 1 Household and shopping characteristics of participants

\begin{tabular}{lllll}
\hline Household characteristics & Maximum & Minimum & Mode & Mean \\
\hline Age (years) & 63 & 19 & 26 & 38 \\
Annual household income ('000 \$) & 170 & 10 & 30 & 58 \\
Family size (including children) & 6 & 1 & 2 & 2.5 \\
Number of children & 3 & 0 & 0 & 0.4 \\
Shopping trips in a month & 12 & 2 & 5 & 5.4 \\
\hline
\end{tabular}

the next week, suggesting that for most participants the next shopping trip refers to purchasing in another outside store. This was especially true in the closing phase of data collection when the timing of the next shopping trip was beyond the experimental period. If a participant decided to buy an SKU without indicating her intention at the pre-questionnaire phase, we could not capture her PRIOR for that SKU. Web Appendix 2 provides a graphical summary of the process.

A snapshot of the shopping screen is in Web Appendix 3. Participants had to browse through all nine category pages in a fixed sequence to finish their shopping experience. Before checking out, they could re-visit any of the previously visited category pages in any order and change any purchase decision.

Table 2 reports the maximum, minimum and average prices, and average PRIORs and POSTs in the nine categories. Price dispersion, both within and across the categories, is substantial. On average, it appears that participants' PRIOR and POST are quite close and realistic when compared to our store prices, implying that participants might be revealing their true price expectations in reports. Some discrepancies (e.g., canned soup) are observed because popular SKUs in that product category that appear more frequently in participants' shopping list are weighted more when calculating the average PRIORs and POSTs.

Purchase behavior of participants is summarized in Table 3. Only $4 \%$ of the transactions are unplanned purchases, i.e., items that the participants have not planned to purchase in the category but end up buying. For $45 \%$ of the transactions, shoppers buy the SKUs that they indicated in the pre-purchase questionnaire. This is close to the study in Block and Morwitz [1] which reported that about $42.8 \%$ of the items purchased were on the shopping list. Within-brand SKU switching, i.e., buying another SKU of the same brand, accounts for $15 \%$ of transactions. Another $26 \%$ of transactions end up with no purchase. Inter-brand competition that induces brand switching accounts only for $10 \%$ of observations. Hence, the critical decision for majority of transactions is "buy vs. not-buy" for planned items. In another study, Gutierrez [20] reported that $76.6 \%$ of shoppers bought the product categories and brands decided on before store visits, which is close to the ratio of the number of observations purchasing same brand as planned to the total number of purchases in our data $(81 \%)$. Yet, Gutierrez' [20] result of $5.3 \%$ brand-switching was lower than our ratio $(10 \%)$, perhaps because of the larger price variation in our experiment (e.g., we have manipulated sudden price increases and decreases, as we will discuss below). Still, the planned vs. non-planned purchasing behaviors from our experiment are in general consistent with results in previous studies.

\subsection{Experimental Manipulations}

1. Pricing conditions: We manipulated price changes in the online store to investigate how these influenced participants' price expectations updating and purchasing decisions. Participants were randomly assigned to one of five different pricing environments for the duration of the experiment. About half of (week, SKU) couples are in the first environment where prices remain constant. The other four pricing environments differed in the rate of change (gradual vs. sudden) of SKU prices and the direction of change (increase vs. decrease). In gradual change cases, prices of the SKU moved strictly monotonically over the weeks, whereas in the case of sudden change, almost all the prices were changed only in the fourth week. As normally seen in the stores, prices of SKUs under the same brand name (within a category) moved in tandem. Number of (week, SKU) combinations, average percent of price change, and its standard deviation of each pricing environment are reported in the left panel of Table 4. There are fewer cases of "sudden increase" and "sudden decrease" because these only happened once in the experiment. It was ensured that SKUs were in counterbalancing pricing environment in any particular week. That is, whenever a participant found price increases for some SKUs in a category, there would be price decreases for some other SKUs in the same category.

The effects of price change on purchase plan and purchase decisions (from weeks 2 to 4) are summarized in the right panel of Table 4. As expected, price decrease helps in converting planned purchases to actual purchases. In particular, actual purchases are slightly more than planned purchases when there is a sudden price decrease, due to unplanned purchase and brand switching. The ratio of actual to planned purchases is significantly lower under increasing price conditions, especially for sudden increase. 
Table 2 Prices, prior, and post across categories (per SKU)

\begin{tabular}{llllll}
\hline Category & Max. price (\$) & Min. price (\$) & Avg. price (\$) & Avg. PRIOR (\$) & Avg. POST (\$) \\
\hline Milk & 2.69 & 1.19 & 2.25 & 2.36 & 2.32 \\
Soft drinks & 3.67 & 0.89 & 2.14 & 2.08 & 2.02 \\
Yogurt & 3.09 & 0.50 & 1.00 & 1.06 & 1.03 \\
Orange juice & 5.99 & 1.65 & 3.57 & 3.19 & 3.22 \\
Canned soup & 3.29 & 1.99 & 2.56 & 1.89 & 2.06 \\
Pasta & 2.49 & 0.50 & 1.01 & 1.25 & 1.18 \\
Pasta sauce & 3.49 & 0.89 & 2.08 & 2.19 & 2.21 \\
Bath tissue & 3.79 & 1.65 & 2.85 & 2.67 & 2.62 \\
Paper towel & 7.59 & 0.89 & 2.82 & 2.25 & 2.18 \\
\hline
\end{tabular}

We further run some simple regression analyses to test how participants purchase and update price expectations under different pricing conditions. Regression models and results are discussed in Web Appendix 4. Overall, participants were more price sensitive under ascending price conditions and, expectedly, the price coefficient for sudden increase is more negative than that for gradual increase. They were also responsive to the disconfirmation of current prices in updating price expectations. These results provide support that participants are responsive in a sensible way to the controlled conditions.

2. Price display: To differentiate the effect of a mere price reduction from that supplemented by other promotions [18] and to explore possible individual differences in sensitivity to this manipulation [21], we selected a set of SKUs for which the price reduction (from the previous week) was accompanied by an on-screen banner stating that the price of the selected SKU was \$X this week (the banner did not provide a reference to the original price). We call this banner a "price display" (see online Appendix 3). About $29 \%$ of SKUs whose prices were reduced had an accompanying price display.

Potential Issues of Data Collection In our experiment, we collected information via a survey. Participants were asked about the products they planned to purchase as

Table 3 Purchase behaviors of participants

\begin{tabular}{ll}
\hline Purchase patterns & $\begin{array}{l}\text { Percentage of } \\
\text { transactions (\%) }\end{array}$ \\
\hline $\begin{array}{l}\text { Impulse purchase (did not plan to buy in category } \\
\text { but end up buying) }\end{array}$ & 4 \\
$\begin{array}{l}\text { Brand switching (planned to buy a different brand } \\
\text { in the category) }\end{array}$ & 10 \\
$\begin{array}{l}\text { SKU switching (planned to buy a different SKU } \\
\text { of the same brand) }\end{array}$ & 15 \\
$\begin{array}{l}\text { Bought as planned (bought the SKU indicated in } \\
\text { the pre-purchase stage) }\end{array}$ & 45 \\
\begin{tabular}{l} 
No purchase \\
\hline
\end{tabular} & 26 \\
\hline
\end{tabular}

well as their PRIORs and POSTs. This method has the potential to create bias in participants' responses. First, the participants might not have planned their purchases but were forced to create a list. We believe that this is not an issue for most of participants. Previous studies have found that most consumers are in the habit of creating a shopping list before shopping [1]. Given that the ratio of planned vs. unplanned purchases in our data is quite consistent with previous studies on shopping lists, as we previously discussed, a survey for plans of purchases does not seem to have created biases in the actual purchasing behavior.

The second potential issue is that by asking for participants' PRIOR, the survey may have "framed" them to alter their subsequent purchase decisions and responses to the POST question. To investigate the extent of such potential bias, we randomly divided the shoppers into two equal groups in the first week of data collection. The control group first completed the online shopping and then responded to questionnaires regarding their PRIOR and POST, while the treatment group was asked for PRIOR before shopping. The results presented in Table 5 show that there is no statistically significant difference in the number of SKUs planned to be purchased and actually purchased between the control and treatment groups. We also find that the average ratio of (Price-POST)/Price is -0.19 (standard deviation at 0.44 ) for the experimental group and -0.23 (standard deviation at 0.53 ) for the control group. There is virtually no difference between the two groups. Therefore, we conclude that asking the PRIOR question has not biased participants' response to POST and purchase decisions in our study.

Finally, the survey of PRIOR and POST may have a "carryover" effect on participants' price expectations in subsequent weeks. It is difficult to investigate the extent of such bias since previous studies [22] have stated that the temporal correlation of attitudes should be high. However, as we will discuss in Section 5, for a large segment of participants, their POST in the previous week has a small 
Table 4 Price changes and purchases

\begin{tabular}{|c|c|c|c|c|c|c|}
\hline \multirow[t]{3}{*}{ Pricing conditions } & \multirow{2}{*}{\multicolumn{3}{|c|}{ Price change }} & \multicolumn{3}{|l|}{ Purchases } \\
\hline & & & & \multicolumn{3}{|c|}{ (Number of unique (week, SKU)) } \\
\hline & $\begin{array}{l}\text { Number of } \\
\text { (week, SKU) }\end{array}$ & $\begin{array}{l}\text { Average change } \\
(\%)\end{array}$ & $\begin{array}{l}\text { Standard } \\
\text { deviation (\%) }\end{array}$ & $\begin{array}{l}\text { Planned } \\
\text { purchases }\end{array}$ & $\begin{array}{l}\text { Actual } \\
\text { purchase }\end{array}$ & $\begin{array}{l}\text { Ratio of actual to } \\
\text { planned purchases (\%) }\end{array}$ \\
\hline Gradual increase & 488 & 10.6 & 9.0 & 425 & 258 & 61 \\
\hline Gradual decrease & 488 & -9.1 & 6.9 & 276 & 221 & 80 \\
\hline Sudden increase & 134 & 56.0 & 53.4 & 85 & 36 & 42 \\
\hline Sudden decrease & 140 & -31.6 & 14.7 & 69 & 75 & 109 \\
\hline No change & 1,271 & - & - & 940 & 679 & 72 \\
\hline
\end{tabular}

impact on their current POST. This contradicts the carryover effect argument.

\section{Model}

We postulate that before walking into our store, consumers have a list (mental if not on paper) of products that they intend to purchase. Consumers also have a PRIOR for each of these SKUs they plan to purchase and possibly an expected price related to purchasing from outside stores. During the purchasing process, a disconfirmation between PRIOR and current price may generate psychological gain or loss (transaction utility). Further, after observing the current price, consumers may update their expected price of purchasing from outside stores, which is the POST we collect after participants finish the shopping process. Consumers may also update their price expectation for the next shopping trip in our store, which will be the PRIOR we collect in the next week.

We only have information of participants' PRIOR and POST if the products are on their shopping list; therefore, we only model the updating process of price expectations and the decision of converting planned purchases into actual purchases. By adopting the latent class model approach [23], our model allows that consumers are heterogeneous in both updating processes and purchase decisions. We model and estimate the updating processes and purchase decisions simultaneously in an integrated framework.

Table 5 Impacts of data collection (analysis for week 1)

\begin{tabular}{llll}
\hline Measure & Group & Avg. & SD \\
\hline No. of SKUs planned & Treatment group & 14.24 & 5.56 \\
& Control group & 12.25 & 4.87 \\
No. of SKUs bought & Treatment group & 6.69 & 2.56 \\
& Control group & 5.50 & 2.17 \\
\hline
\end{tabular}

\subsection{Updating Processes for PRIOR and POST}

Because of the large price variation across the products in our experiment, we normalize both PRIOR and POST by the average price of each of the SKUs. Following the previous literature (e.g., Nerlove's [10] "adaptive expectation” model), we postulate that for consumer $i$ in week $t$ who belongs to a latent class $s$, the updating process of PRIOR for product $j$ is as follows:

$$
\begin{aligned}
\frac{\mathrm{PRIOR}_{i j t}}{\overline{p_{j}}}= & \theta_{0}^{s}+\theta_{1}^{s} \cdot \frac{\mathrm{PRIOR}_{i j, t-1}}{\bar{p}_{j}}+\theta_{2}^{s} \cdot \frac{\left(\mathrm{PRICE}_{j, t-1}-\mathrm{PRIOR}_{i j, t-1}\right)}{\bar{p}_{j}} . \\
& \left\{\left|\frac{\left(\mathrm{PRICE}_{j, t-1}-\mathrm{PRIOR}_{i j, t-1}\right)}{\bar{p}_{j}}\right| \geq k_{1}^{s}\right\}+\varepsilon_{i j t}
\end{aligned}
$$

where $\bar{p}_{j}$ is the average price of product $j$, and the superscript $s$ implies that the $(i, j, t)$ tuple belongs to a latent class $s$. The difference $\left(\mathrm{PRICE}_{j, t-1}-\mathrm{PRIOR}_{i j, t}\right.$ -1 ) allows us to see how much of the previous disconfirmation is incorporated by consumers in forming their current expectation. The indicator function $\{\cdot\}$ in the equation implies that consumers will only update their PRIOR if the ratio $\left|\left(\mathrm{PRICE}_{j, t-1}-\mathrm{PRIOR}_{i j, t-1}\right) / \overline{p_{j}}\right|$ is large than a positive parameter $k_{1}^{s}$, i.e., when the difference is outside their zone of insensitivity. To allow for model flexibility, we do not impose the restriction that $\theta_{1}^{s}=\left(1-\theta_{2}^{s}\right)$ as in the standard exponential smoothing model. Finally, the error term $\varepsilon_{i j t}$ is assumed to be distributed as $N\left(0, \sigma_{1}^{2}\right)$.

Our POST updating model is similar to Eq. (1). Although POST is related to the price in stores outside, participants may still use observed prices in our online store to update their expectations, especially if they are uncertain of the prices outside. We hypothesize that the previous period $\operatorname{POST}_{i j, t-1}$ provides a prior and 
consumers update their $\operatorname{POST}_{i j t}$ after observing the current price in the online store. For consumer $i$ in week $t$ who belongs to a latent class $s$, the updating process is as follows:

$$
\begin{aligned}
\frac{\operatorname{POST}_{i j t}}{\bar{p}_{j}}= & \beta_{0}^{s}+\beta_{1}^{s} \cdot \frac{\mathrm{POST}_{i j, t-1}}{\bar{p}_{j}}+\beta_{2}^{s} \cdot \frac{\left(\mathrm{PRICE}_{j t}-\mathrm{POST}_{i j, t-1}\right)}{\bar{p}_{j}} . \\
& \left\{\left|\frac{\left(\mathrm{PRICE}_{j t}-\mathrm{POST}_{i j, t-1}\right)}{\bar{p}_{j}}\right| \geq k_{2}^{s}\right\}+\eta_{i j t}
\end{aligned}
$$

where the error term $\eta_{i j t}$ is assumed to be distributed as $N\left(0, \sigma_{2}^{2}\right)$, and $k_{2}^{s}$ is another positive parameter that measures the zone of insensitivity for this process. Note that in Eq. (2), $\mathrm{POST}_{i j t}$ is updated from PRICE $j$. Our hypotheses state that for at least one class, the parameters $\theta_{2}^{s}$ in Eq. (1) and $\beta_{2}^{s}$ in Eq. (2) are both zero, while for another class, both parameters are significantly positive. ${ }^{3}$

\subsection{Purchase Decisions}

Conditional on PRIOR and POST, a consumer's utility of purchase is captured by a reduced-form specification. For a product $j$ in consumer $i$ 's shopping list in period $t$ that belongs to latent class $s$, we specify the purchase utility function as:

$$
\begin{aligned}
u_{i j t}=\delta_{0}^{s} & +\delta_{1}^{s} \ln \left(\frac{\mathrm{PRICE}_{j t}}{p_{j}}\right)+\delta_{2}^{s} \ln \left(\frac{\mathrm{PRICE}_{j t}}{\text { PRIOR }_{i j t}}\right) \cdot\left\{\left|\ln \left(\frac{\mathrm{PRICE}_{j t}}{\text { PRIOR }_{i j t}}\right)\right| \geq k_{3}^{s}\right\} \\
& +\delta_{3}^{s} \ln \left(\frac{\text { PRICE }_{j t}}{\operatorname{POST}_{i j t}}\right) \cdot\left\{\left|\ln \left(\frac{\mathrm{PRICE}_{j t}}{\mathrm{POST}_{i j t}}\right)\right| \geq k_{4}^{s}\right\}+\delta_{4}^{s} \text { Display }_{j t}+v_{i j t}
\end{aligned}
$$

The parameter $\delta_{1}^{s}$ measures the consumer price sensitivity, $\delta_{2}^{s}$ the effect of gain or loss when current price is different from PRIOR on the transaction utility, and $\delta_{3}^{s}$ the difference between the expected purchase cost from outside stores and the current price. The parameter $\delta_{4}^{s}$ measures the effect of price display on the utility of purchase. Similar to Eqs. (2) and (3), the two indicator functions in the equation imply that PRIOR and POST will only impact the purchase decision if the absolute values of $\ln \left(\mathrm{PRICE}_{j t} / \mathrm{PRIOR}_{i j t}\right)$ and $\ln \left(\mathrm{PRICE}_{j t} /\right.$ $\operatorname{POST}_{i j t}$ ) are larger than $k_{3}^{s}$ and $k_{4}^{s}$, respectively. We hypothesize that for one (high-effort) class, $\delta_{1}^{s}$ and $\delta_{3}^{s}$ in the equation are significantly negative, while for the other (low-effort) class, $\delta_{2}^{s}$ is significantly negative.

\footnotetext{
${ }^{3}$ We have also estimated an asymmetric model allowing $\theta$ and $\beta$ to be different when current prices are higher (vs. lower) than expectations in Eqs. (1) and (2). We do not find any significant asymmetric differences.
}

Following a standard approach, we assume that the utility generated from the decision of not buying the planned item from our store (and instead from an outside stores) is $u_{i 0 t}=v_{i 0 t}$.

We assume that the stochastic variables $v_{i 0 t}$ and $v_{i j t}$ in Eq. (3) belong to type 1 extreme value distribution. Let $y_{i j t}$ be an indicator function which is equal to 1 if a purchase is made, and 0 otherwise, and let $\widehat{u}_{i j t}^{s}$ be the deterministic part in Eq. (3) without $v_{i j t}$. The probability that a planned item $j$ will be converted to actual purchase has the following binary logit specification:

$P_{i j t}^{s}=\operatorname{Pr}^{s}\left(y_{i j t}=1\right)=\exp \left(\hat{u}_{i j t}^{s}\right) /\left[1+\exp \left(\stackrel{(}{s}_{i j t}^{s}\right)\right]$

\subsection{Class Membership}

Let $f_{i j t}^{s}$ be the probability that the $(i, j, t)$ tuple belongs to a latent class $s$. We assume a logit form specification as:

$f_{i j t}^{s}=\exp \left(Z_{i j t} \theta^{s}\right) / \sum_{s^{\prime}} \exp \left(Z_{i j t} \theta^{s^{\prime}}\right)$

where $Z_{i j t}$ is a vector of the covariates. As discussed in Section 2, both situational and intrinsic variables determine the consumer's effort level to process information [24]. We use a vector of time-invariant covariates including "Freq_Shop ${ }_{i}$," which equals 1 if consumer $i$ visits a grocery store more than five times (the average for our data) in a month and 0 otherwise; " $\ln \left(\operatorname{Inc}_{i}\right)$," which is the $\log$ of the household annual income of the consumer; and "Fav_Brand ${ }_{i j}$ ", which is an indicator variable that takes the value 1 if product $j$ belongs to the consumer $i$ 's favorite brand. We also use a covariate "PriorConfidence $i j t$ " which is the consumer's confidence level when she estimates PRIOR for the product. Finally, consumers may switch their effort level in the shopping process, depending on the price stimuli. We use the percentage price increase from the last period (PriceDiff-Positive), and percentage price decrease from the last period (PriceDiff-Negative), to represent the ascending and decreasing pricing conditions. Incorporating these two variables in Eq. (5) helps us to investigate how the effort level of information processing will be affected under the price manipulation in our experiment.

\subsection{Model Estimation}

Conditional on belonging to a class $s$, we assume that $\varepsilon$ s in the PRIOR updating (Eq. (1)), $\eta \mathrm{s}$ in the POST updating (Eq. (2)), and $v$ s in the purchase utility function (Eq. (3)) are independent of each other. In other words, the interdependence of price expectations updating and purchase decisions is fully 
captured by the latent class membership. Based on this assumption, and the fact that the updating processes do not depend on the purchase decision, we can specify the joint likelihood of PRIOR $i j t$, POST $_{i j t}$, and purchase decisions $y_{i j t}$ as

$\ell=\sum_{i, j, t} \ln \left[\sum_{s} f_{i j t}^{s} \times\left(L^{1}\left(\mathrm{PRIOR}_{i j t} \mid s\right) \times L^{2}\left(\operatorname{POST}_{i j t} \mid s\right) \times L^{3}\left(y_{i j t} \mid \operatorname{PRIOR}_{i j t}, \operatorname{POST}_{i j t}, s\right)\right)\right]$

where $L^{1}$ is the conditional density function in Eq. (1), $L^{2}$ the conditional density function in Eq. (2), and $L^{3}=\left[P_{i j t}^{s}\right]^{y_{i j t}}\left[1-P_{i j t}^{s}\right]^{\left(1-y_{j i t}\right)}$ the likelihood function conditional on PRIOR ${ }^{i j t}$ and $\operatorname{POST}^{i j t}$, where $P^{i j t}$ is the purchase probability function in Eq. (4). To allow for the possible heteroskedasticity of $\varepsilon$ and $\eta$ across product categories (see Eqs. (1) and (2)), we estimate categoryspecific $\sigma^{1}$ and $\sigma^{2}$.

In the experiment, participants may need some time to experience and learn about our store and its prices. In particular, they need to learn how to form their PRIOR by first observing our store prices. Therefore, we only use data from the last 4 weeks (weeks 2-5) in model estimation. Week 2 provides data for PRIOR $^{i j, t-1}$ for model estimation, and the last 3 weeks provide data to estimate the full model in Eq. (6). Overall, we have 943 complete data points that include PRIOR, POST, and the purchase decisions.

\subsection{Model Limitations}

We only estimate the decision of converting planned purchases into actual purchases from a binary choice model. Competitive effects from other products within the store are not fully specified. This is primarily due to the fact that it would be impractical to elicit expectations for all the SKUs that are on offer each week from every buyer. To address the issue of missing competitive effect in our model, we have tried to balance the price effect across participants and across product categories: when some participants see in a week that a product $\mathrm{X}$ is priced lower than the previous week, about the same number of other participants would see the product priced higher. Also, for each participant, the number of products with ascending price is about the same as the number of products with descending price. Hence, the competition effect from other products in our store should roughly cancel out at the aggregate level. Moreover, Table 3 shows that only $14 \%$ of transactions in our observations involve unplanned purchases or brand switching. Therefore, we believe that our binary choice model captures the major component of consumer decision-making in our data.

Another limitation in our analysis is that it is conditional to the list of products that our participants intend to purchase. We do not model how this list is generated, which is possibly based on participants' current price expectations and previous purchase experience. Though it is important to understand how consumers plan their purchases before visiting stores, it is beyond the scope of our research to model all possible combinations of the available 89 SKUs in our store that form the shopping list.

\section{Result}

Consistent with theories of dual-process models of information processing, we have estimated the latent class model in Eq. (6), allowing for the existence of two classes. ${ }^{4}$ To further test the consistency of our results with the hypotheses we proposed in Section 2, and for the reason that we will discuss below, we have also estimated a "structural heterogeneity" model that was developed in Kamakura et al. [25] (for another application, see [26]). Under this approach, researchers would impose restrictions on some of the behavioral parameters for different latent classes that are consistent with a priori structural assumptions. We explicitly restrict the updating and purchasing behavior of the two classes for it to be consistent with hypotheses $\mathrm{H} 1$ and $\mathrm{H} 2$. Further details will be provided below. Estimation results of the two models are reported in Table 6.

We first discuss the results of the latent class model. The PRIOR and POST updating estimates are presented in the first and second panels. For class 1 (the first column of estimates), PRIOR is quickly updated if there is a disconfirmation between previous week's price and PRIOR. The positive coefficient implies that the more positive is the disconfirmation, the higher is the PRIOR in the next week. The smaller magnitude coefficient for class 2 (the second column of estimates) in

\footnotetext{
${ }^{4}$ We also estimate one- and three-class models. The one-class model performs worse than the others based on both AIC and BIC. Although the three-class model is better than the two-class model based on AIC, the additional transaction class is small in size (about $9 \%$ ) that is split from the larger class in the two-class model. Other parameter estimates are similar. To test our hypotheses directly, based on dual-process information processing, we choose to focus only on the two-class model. We also estimate several alternative models to check the robustness of the results presented here. For example, we estimate a model allowing for a consumer-specific random effect on class membership. That is, we assume a stochastic term $\xi_{i}$ for each participant $i$ in Eq. (5) that is fixed across products and weeks. The magnitude of this effect is not significant in our estimation, and other estimates are very similar to what we shall present.
} 
Table 6 Parameter estimates of the two-class model

\begin{tabular}{|c|c|c|c|c|c|}
\hline & \multirow[t]{2}{*}{ Parameter } & \multicolumn{2}{|c|}{ Latent class model } & \multicolumn{2}{|c|}{$\begin{array}{l}\text { Structural heterog. } \\
\text { model }\end{array}$} \\
\hline & & $\begin{array}{l}\text { Class } 1 \\
\text { Estimate }\end{array}$ & $\begin{array}{l}\text { Class } 2 \\
\text { Estimate }\end{array}$ & $\begin{array}{l}\text { Class } 1 \\
\text { Estimate }\end{array}$ & $\begin{array}{l}\text { Class } 2 \\
\text { Estimate }\end{array}$ \\
\hline \multirow[t]{3}{*}{ Updating: PRIOR formation } & Const1 & $0.15^{\mathrm{a}}$ & $0.21^{\mathrm{a}}$ & $0.17^{\mathrm{a}}$ & $0.14^{\mathrm{a}}$ \\
\hline & $\mathrm{PRIOR}_{t-1} / \bar{p}$ & $0.83^{\mathrm{a}}$ & $0.80^{\mathrm{a}}$ & $0.81^{\mathrm{a}}$ & $0.86^{\mathrm{a}}$ \\
\hline & $\begin{array}{l}\left(\text { PRICE }_{t-1}-\text { PRIOR }_{t-1}\right) / \bar{p} \\
\text { Updating threshold }\left(k_{1}^{s}\right)\end{array}$ & $\begin{array}{l}0.58^{\mathrm{a}} \\
0.12^{\mathrm{a}}\end{array}$ & $\begin{array}{l}-0.07^{\mathrm{a}} \\
0.06\end{array}$ & $\begin{array}{l}0.57^{\mathrm{a}} \\
0.12^{\mathrm{a}}\end{array}$ & \\
\hline \multirow[t]{4}{*}{ Updating: POST formation } & Const2 & $0.22^{\mathrm{a}}$ & $0.91^{\mathrm{a}}$ & $0.23^{\mathrm{a}}$ & $0.90^{\mathrm{a}}$ \\
\hline & $\operatorname{POST}_{t-1} / \bar{p}$ & $0.74^{\mathrm{a}}$ & $0.06^{\mathrm{a}}$ & $0.73^{\mathrm{a}}$ & $0.06^{\mathrm{a}}$ \\
\hline & $\left(\mathrm{PRICE}_{t}-\mathrm{POST}_{t-1}\right) / \bar{p}$ & $0.73^{\mathrm{a}}$ & -0.01 & $0.73^{\mathrm{a}}$ & \\
\hline & Updating threshold $\left(k_{2}^{S}\right)$ & 0.06 & 0.07 & $0.03^{\mathrm{a}}$ & \\
\hline \multirow[t]{7}{*}{ Purchase decision } & Const3 & $0.53^{\mathrm{a}}$ & $-0.82^{\mathrm{a}}$ & $0.59^{\mathrm{a}}$ & $-0.80^{\mathrm{a}}$ \\
\hline & Display & 1.95 & $0.59^{\mathrm{b}}$ & 1.87 & $0.59^{\mathrm{b}}$ \\
\hline & $\ln \left(\mathrm{PRICE}_{t} / \bar{p}\right)$ & $-1.43^{\mathrm{b}}$ & -0.37 & -1.24 & -0.30 \\
\hline & $\ln \left(\mathrm{PRICE}_{t} / \mathrm{PRIOR}_{t}\right)$ & 1.17 & $-1.16^{\mathrm{a}}$ & & $0.59^{\mathrm{a}}$ \\
\hline & $\begin{array}{l}k_{3}^{s} \text { : threshold for } \ln \left(\mathrm{PRICE}_{t} /\right. \\
\left.\text { PRIOR }_{t}\right)\end{array}$ & 0.00 & 0.00 & & -0.02 \\
\hline & $\ln \left(\mathrm{PRICE}_{t} / \mathrm{POST}_{t}\right)$ & $-5.06^{\mathrm{a}}$ & $0.66^{\mathrm{a}}$ & $-4.23^{\mathrm{a}}$ & \\
\hline & $\begin{array}{l}k_{4}^{s}: \text { threshold for } \ln \left(\mathrm{PRICE}_{t} /\right. \\
\left.\text { POST }_{t}\right)\end{array}$ & $0.04^{\mathrm{b}}$ & 0.14 & $0.05^{\mathrm{b}}$ & \\
\hline \multirow{8}{*}{$\begin{array}{l}\text { Probability function estimates } \\
\text { for class } 1\end{array}$} & Const & $-1.05^{\mathrm{a}}$ & & $-1.21^{\mathrm{a}}$ & \\
\hline & PriceDiff-Negative & $8.41^{\mathrm{a}}$ & & $8.13^{\mathrm{a}}$ & \\
\hline & PriceDiff-Positive & -1.03 & & -1.01 & \\
\hline & Fav_Brand & $1.37^{\mathrm{a}}$ & & $1.37^{\mathrm{a}}$ & \\
\hline & PriorConfidence & 0.03 & & 0.05 & \\
\hline & Display & -10.47 & & -9.63 & \\
\hline & $\ln ($ Inc $)$ & $-0.08^{\mathrm{a}}$ & & $-0.09^{\mathrm{a}}$ & \\
\hline & Freq Shop & 0.32 & & 0.34 & \\
\hline
\end{tabular}

${ }^{\text {a }}$ Significant at $5 \%$ or better

${ }^{\mathrm{b}}$ Significant at $10 \%$ largest in magnitude among all parameters. Thus, purchases of this class are driven by the comparison of the cost of buying now and the expected cost of buying later in an outside store. In contrast, for class $2, \ln \left(\mathrm{PRICE}_{t} / \mathrm{PRIOR}_{t}\right)$ is the most important variable (estimated coefficient at -1.16 ), showing that the purchase decision of this class is primarily driven by the psychological gain or loss due to the difference between the actual price and the PRIOR of the store. The coefficient for $\ln \left(\mathrm{PRICE}_{t} / \bar{p}\right)$ for class 1 is significantly negative, while that for class 2 is small and insignificant, indicating that the latter class is not price sensitive. However, for the latter class, price displays have a strong positive effect on purchase decisions. ${ }^{5}$ Finally, for class 1 , the threshold for $\ln \left(\mathrm{PRICE}_{t} / \mathrm{POST}_{t}\right), k_{4}^{s}$, implies that POST will only impact the purchase decision of this class when the disconfirmation between store price and POST is larger than $4 \%$. Other threshold estimates are not significant.

\footnotetext{
${ }^{5}$ Marginally statistical significance ( $p$ value at 0.06 ) with only 36 instances ( $4 \%$ of transactions) of price display.
} 
All of the above results are consistent with our hypotheses $\mathrm{H} 1$ and $\mathrm{H} 2$ in Section 2; however, we are concerned that for class 2 , the coefficient of $\ln \left(\mathrm{PRICE}_{t} / \mathrm{POST}_{t}\right)$ is significantly positive. One possible explanation of this result is that consumers in this class have not considered POST during the purchasing process; hence, their responses to the postquestionnaire were systematically biased, which might have led to the spurious relationship in model estimation. To check how our findings are affected by including POST in the purchase decisions for class 2 , we have estimated a structural heterogeneity model. Theories of dual information processing predict the existence of distinct PRIOR and POST updating and purchasing behaviors. Based on the prediction, we restrict the coefficients for $\ln \left(\mathrm{PRICE}_{j t} / \mathrm{POST}_{i j t}\right) \quad\left(\delta_{3}^{s}\right)$ in Eq. (3), updating parameters $\theta_{2}^{s}$ in Eq. (1) and $\beta_{2}^{s}$ in Eq. (2) to be zero for one (low-effort) class and for another (high-effort) class the coefficient for $\ln \left(\mathrm{PRICE}_{j t} / \mathrm{PRIOR}_{i j t}\right) \quad\left(\delta_{2}^{s}\right)$ in Eq. (3) to be zero. That is, for the former class purchase, decisions are independent from POST, and its price expectations are stable over time, while for the latter class purchase, decisions are not impacted by the PRIOR. Almost all parameter estimates of the structural heterogeneity model, shown on the right panels in Table 6, are very similar to the latent class model. The only significant changes are that the magnitudes of the coefficients of $\ln \left(\mathrm{PRICE}_{t} / \mathrm{POST}_{t}\right)$ for class 1 and $\ln \left(\mathrm{PRICE}_{t} / \mathrm{PRIOR}_{t}\right)$ for class 2 have become smaller. As before, for class 1, the most important factor for purchase decisions is POST and for class 2 is PRIOR.

Given that for most participants POST is the price that they expect to pay in an outside store, we label class 1 the outsidelooking (OL) class. In contrast, class 2 makes decisions based on the prior expected price (PRIOR) and the actual price of the same store, and outside stores are not considered (at least for the structural heterogeneity model). Therefore, we label class 2 the inside-focused (IF) class.

The bottom panels in Table 6 report the parameter estimates in the probability function for a transaction to belong to the OL class (see Eq. (6)). First, the intercept term is significantly negative $(-1.05$ in the latent class model and -1.21 in the structural heterogeneity model), implying that on average, the size of the OL class is much smaller than that of the IF class. That is, about $70 \%$ of transactions in our data are in the IF class, implying that for most of our participants the comparison of prior price expectations and actual store prices dictates the decisions of converting planned to actual purchases. Furthermore, while the coefficient for "PriceDiff-Positive" is insignificant, that for "PriceDiff-Negative" is significantly positive in both models. This implies that a reduction in price from last week greatly increases the probability of the transaction being in the IF class. Since price decrease may generate a large psychological gain for consumers, they will be less motivated to consider prices in outside stores.
Consumers are more likely to belong to the OL class while buying their favorite brand, as they are more motivated to process information carefully [11], including the consideration of outside alternatives. The coefficient for price display (Display), though negative with large magnitude, is not statistically significant, perhaps due to the fact that we only have limited number of observations. For the individual-specific factors, we find that shoppers with a lower household income are more likely to belong to the OL class. However, the coefficient for being a frequent shopper is not statistically significant.

To conclude, the above results suggest that the group of consumers who are unlikely to invest high effort in processing price information belongs to the larger IF class. They focus on comparing store prices and their prior expectations, without considering the alternative of buying from outside stores. These consumers are also less sensitive to store price changes. Their PRIOR and POST are updated much slower than the OL class. These findings support our hypotheses $\mathrm{H} 1$ and $\mathrm{H} 2$. Transaction-specific and individual-specific factors may affect the effort level in the shopping process. In particular, price promotions will increase the probability of a participant belonging to the IF class. These are consistent with our hypothesis H3.

\section{Implications of Consumer Price Expectations and Managerial Takeaways}

\subsection{Managing Frequency and Depth of Price Promotions}

In a typical store following Hi-Lo pricing, retailers have to decide how frequent and how deep price promotions should be offered in order to maximize sales increase. Using our results, we conduct "what-if" price experiments to help shed light on this issue. We choose a representative SKUFlorida's Natural 64 oz.- from the refrigerated orange juice category. Florida's Natural is a popular brand with a share of about $17 \%$ from not-from-concentrate market and about $10 \%$ from the total chilled juice market. The regular price is $\$ 2.30$. We assume that our store is facing the following three alternative promotion schemes: (1) price cut at $3 \%$ (priced at $\$ 2.23$ ) over 5 weeks; (2) price cut at $5 \%$ (priced at \$2.19) for the first 3 weeks, then back to the regular price for the last 2 weeks; and (3) price cut at $15 \%$ (priced at \$1.96) in the first week, then back to the regular price for the next 4 weeks. We assume in each week a typical consumer visits the store with Florida's Natural in her shopping list. We abstract away from the impacts of price promotion on store traffic and brand switching; instead, we focus on the impacts of promotional schemes in converting customer-planned purchase to actual purchase. Therefore, the results below should be viewed as conditional on store visits and planned purchases. 
We further assume that without price promotion, the consumer's PRIOR and POST are at \$2.30. However, seeing a price promotion in store, she will update her POST, as our results suggest. Conditional on being in the IF or OL class, we compute the purchase probability under each of the promotion schedules. Different levels of promotions will also change the size of the two classes (the coefficient for PriceDiff-Negative is significantly positive). Accordingly, we compute the class membership probabilities and then calculate the expected purchase probability weighted by these probabilities. Finally, we calculate the demand elasticity. Since the average price cut per week is $3 \%$ under the three promotional schemes, the elasticity is computed as the percentage change in total purchase probability over 5 weeks divided by $-3 \%$.

The result, based on the latent class model and the structural heterogeneity model, is summarized in Fig. 1. Overall results of both models are highly consistent - a deeper discount such as $5 \%$ price cut for 3 weeks or a one-time $15 \%$ price cut generates a higher elasticity than small discount such as $3 \%$ price cut for 5 weeks (about -0.65 under the 5 and $15 \%$ cuts vs. -0.5 under the $3 \%$ cut using the latent class model, and about -0.72 vs. -0.62 , respectively, using the structural heterogeneity model). A deeper investigation reveals that demand elasticity for the IF class is about the same for the three promotions. The increase comes from the OL class: a $3 \%$ price cut does not pass the threshold for POST updating (0.12) for the OL class; hence, its POST will remain

\section{(A) Latent Class Model}

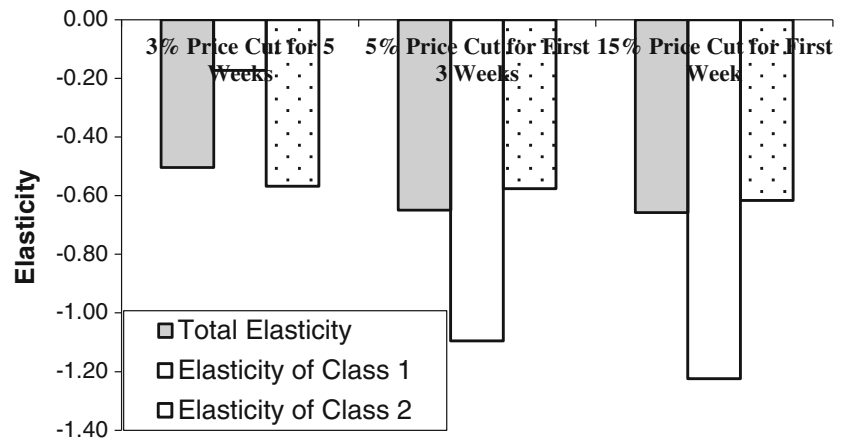

(B) Structural Heterogeneity Model

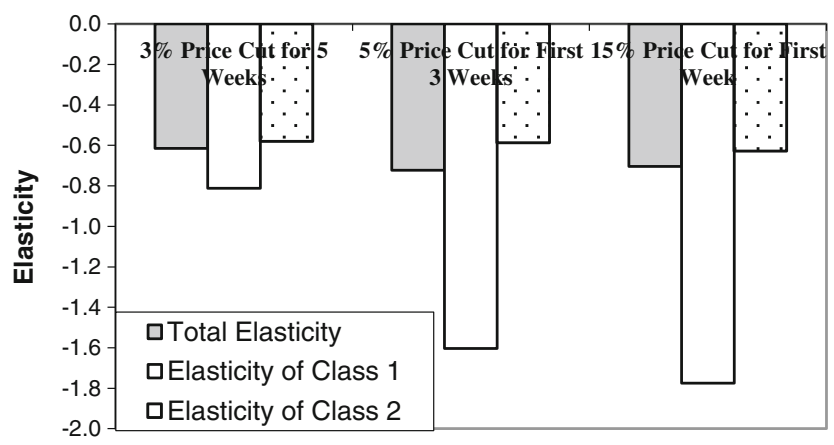

Fig. 1 Price elasticities under different promotional schemes

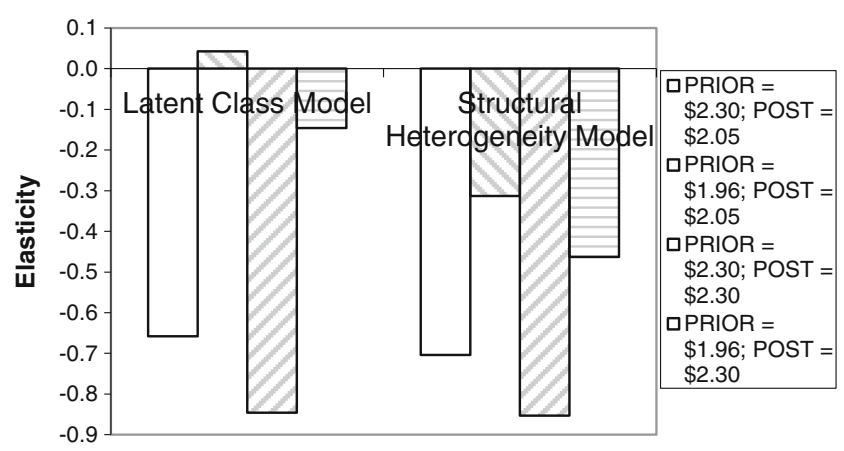

Fig. 2 Price elasticities under different scenarios of price expectations

the same. The price cut also does not pass the threshold for POST to impact the purchase probability $(0.04)$. The combined result is that consumers in this class are not responsive to the $3 \%$ price cut. With a larger price cut ( 5 or $15 \%$ ), demand of the OL class will become more elastic. The deeper the price discount, the higher the demand elasticity. However, another factor will counteract the increase in elasticity-the larger the price discount the more likely that consumers will fall into the IF class, which is far less responsive to the store price change. We find that the IF class size grows from $84 \%$ under the $3 \%$ discount to $93 \%$ under the $15 \%$ discount. Hence, our first key managerial takeaway that is also consistent with intuition provided by prior experimental work [27]:

Takeaway \#1 A deep price discount over shorter duration will increase sales more than several shallow discounts over a longer duration.

Takeaway \#2 A deep price discount will switch more consumers to the IF class, whose purchase decisions are influenced by the disconfirmation between store price and PRIOR.

\subsection{Managing Price Expectations During Promotions}

The importance of managing price expectations during promotions is illustrated in this section. Retailers often use communication strategies to supplement price promotions. Feature advertisement, for example, informs potential customers about price promotions thus may increase store traffic, but they may also have consequences on consumers' price expectations. Consumers who see retailer's feature advertisements before walking into the store will lower their PRIOR to the new low level. Consequently, the retailer does not get the benefit of a favorable disconfirmation. Also, POST of the OL class, which is more responsive to price promotion, will be partially downward adjusted with price promotion as consumers may expect similar deals from other stores. An in-store promotion tag informing that such deals are not available at other stores (e.g., "Price \$Y only in our store") may convince this class not to lower its 
POST. We use what-if scenarios to illustrate how different price expectations may impact sales, assuming that during promotion a retailer decides to cut the price of Florida's Natural juice by $15 \%$ from $\$ 2.30$ to $\$ 1.96$.

Suppose the retailer reduces the price without any announcement. The PRIOR of both classes remains at $\$ 2.30$, but POST of the OL class will be lowered to $\$ 2.05$. Price is lower than PRIOR and POST leading to an expected demand elasticity of -0.66 using the latent class model and -0.70 using the structural heterogeneity model (first bar from each set in Fig. 2). Alternatively, if consumers were informed of the price cut (e.g., through feature advertisement), their PRIOR is updated to $\$ 1.96$. The updated POST of the OL class is still $\$ 2.05$. Without the favorable disconfirmation between current price and PRIOR, the purchase probability of the IF class will be vastly reduced. As a result, the overall demand elasticity is lower than the first scenario (see the second bar from each set in Fig. 2). ${ }^{6}$

Assume that the price is cut without any announcement, which leads to a favorable disconfirmation between the current price and PRIOR, as in the first scenario. We further assume that consumers' POST is not updated following the price promotion (e.g., with an on-the-shelf tag that says "Price $\$ 1.96$ only in our store"), leading to a greater favorable disconfirmation between price and POST. This leads to an increase in purchases from the OL class. This is the "best" scenario for the store as the demand elasticity is the highest using both model results (see the third bar from each set). Finally, the fourth scenario illustrates the outcome when PRIOR is fully updated to $\$ 1.96$ but POST is not. In this case, demand elasticity (the fourth bar from each set in Fig. 2) is smaller than the third scenario.

Takeaway \#3 Managing price expectations is important for the effectiveness of price promotions. Maintaining consumers' PRIOR and POST unchanged will maximize the sales increase.

\section{Conclusion and Future Work}

We set up a controlled online store shopping environment to examine the extent that PRIOR and POST separately influence consumers' purchase decisions. During the 5-week window, shoppers made real purchase decisions, allowing us to collect rich data including their shopping plan and price expectations. From the estimation results, we find that there are two distinct classes of shopping behaviors in our data.

\footnotetext{
${ }^{6}$ Demand elasticity is 0.04 because more consumers switch to the IF class during the promotion, which is not benefited from the favorable disconfirmation between current price and PRIOR.
}

Purchase decisions of the IF class are driven by the difference between actual price and PRIOR at the same store while that of the OL class by the perceived difference between actual price and POST. The IF class is less price sensitive and less active in updating its price expectation and has a much larger segment size. These results support our hypotheses that are developed from the dual information processing theories.

Our study is the first in the marketing literature to provide evidence that, under different market environments, consumers' purchase decisions are influenced by the two types of price expectations in different ways. The results also help retailers to understand the impact of different pricing and promotion strategies and offer important managerial takeaways. We use the results to explain why a promotion scheme with deep discounts may increase store sales more than several shallow discounts over a longer duration. We also show that deep discounts may switch consumers to the IF class, whose purchase decisions are mainly driven by the PRIOR. Finally, we illustrate the importance of managing price expectations when running a price promotion. To maximize the sales increase, it is important for stores to maintain consumers' PRIOR and POST unchanged.

We have acknowledged some of the limitations of our analysis, including ignoring the competitive effects from other products and that it is conditional on the list of products that our participants plan to purchase, and discussed mitigating actions. We also realize that our setup gives high internal validity but somewhat limited external validity. Field experiments in real stores would provide a good reality check of our results. It is important for future research to address these issues.

Acknowledgments The authors acknowledge the generous financial support from the Center for Research in Economics and Strategy (CRES), Olin School of Business, Washington University in St. Louis.

\section{References}

1. Block LG, Morwitz VG (1999) Shopping lists as an external memory aid for grocery shopping: influences on list writing and list fulfillment. J Constr Psychol 8:343-375

2. Monroe KB (1973) Buyers' subjective perceptions of price. J Mark Res 10:70-80

3. Thaler R (1985) Mental accounting and consumer choice. Mark Sci 4:199-214

4. Kahneman D, Tversky A (1979) Prospect theory: an analysis of decision under risk. Economics 47:263-291

5. Krishnamurthi L, Mazumdar T, Raj SP (1992) Asymmetric response to price in consumer brand choice and purchase quantity decisions. $\mathrm{J}$ Constr Res 19:387-399

6. Narasimhan C (1989) Incorporating consumer price expectations in diffusion models. Mark Sci 8:343-357

7. Erdem T, Imai S, Keane MP (2003) Brand and quantity choice dynamics under price uncertainty. Quant Mark Econ 1:5-64 
8. Kalwani MU, Yim CK (1992) Consumer price and promotion expectations: an experimental study. J Mark Res 29:90-100

9. Krishna A, Johar GV (1996) Consumer perception of deals: biasing effects of varying deal prices. J Exp Psychol 2:187-206

10. Nerlove M (1958) Adaptive expectations and cobweb phenomena. Quar J Ecol 72:227-240

11. Cacioppo JT, Petty RE (1982) The need for cognition. J Pers Soc Psychol 42:116-131

12. Shiffrin RM, Schneider W (1977) Controlled and automatic human information processing: II. Perceptual learning, automatic attending and a general theory. Psychol Rev 84:127-190

13. Chaiken $S$ (1980) Heuristic versus systematic information processing and the use of source versus message cues in persuasion. J Pers Soc Psychol 39:752-756

14. Sloman SA (1996) The empirical case of two systems of reasoning. Psychol Bull 119:3-22

15. Kruglanski AE, Orehek E (2007) Partitioning the domain of social inference: dual mode and systems models and their alternatives. Ann Rev Psychol 58:291-316

16. Stanovich KE, West RF (2000) Individual differences in reasoning: implications for the rationality debate? Behav Brain Sci 23:645-665

17. Kahneman D (2003) Maps of bounded rationality: psychology for behavioral economics. Am Ecol Rev 93:1449-1475
18. Inman JJ, McAlister L, Hoyer WD (1990) Promotion signal: proxy for a price cut? J Constr Res 17:74-81

19. Lynch J, de Chernatony L (2007) Winning hearts and minds: business-to-business branding and the role of the salesperson. $\mathrm{J}$ Mark Manag 23:123-135

20. Gutierrez BPB (2004) Determinants of planned and impulse buying: the case of the Philippines. Asia Pac Manag Rev 9:1061-1078

21. Inman JJ, Peter AC, Raghubir P (1997) Framing the deal: the role of restrictions in accentuating deal value. J Constr Res 24:68-79

22. Jacoby J, Morrin M, Jaccard J, Gurhan Z, Kuss A, Maheswaran D (2002) Mapping attitude formation as a function of information input: on-line processing models of attitude formation. J Constr Psychol 12: 21-34

23. Kamakura WA, Russell GJ (1989) A probabilistic choice model for market segmentation and elasticity structure. J Mar Res 26:379-390

24. Celsi RL, Olson JC (1988) The role of involvement in attention and comprehension processes. J Constr Res 15:210-224

25. Kamakura WA, Kim B, Lee J (1996) Modeling preference and structural heterogeneity in consumer choice. Mark Sci 15:152-172

26. Moon S, Russell GJ, Duvvuri SD (2006) Profiling the reference price consumer. J Retail 82:1-11

27. Alba JW, Mela CF, Shimp TA, Urbany JE (1999) The effect of discount frequency and depth on consumer price judgments. J Constr Res 26:99-114 